\title{
Effects of Surgery Combined with Chemoradiotherapy on Short- and Long-Term Outcomes of Early-Stage Nasopharyngeal Carcinoma
}

This article was published in the following Dove Press journal: Cancer Management and Research

\author{
Jing-Jin Weng $\mathbb{D}^{*}$ \\ Jia-Zhang Wei (iD* \\ Min Li \\ Shao-Jie Zhang \\ Yun-Zhong Wei \\ Han-Wei Wang \\ Dan-Xue Qin \\ Jin-Long Lu \\ He Jiang \\ Shen-Hong Qu
}

Department of Otolaryngology \& Head and Neck, The People's Hospital of Guangxi Zhuang Autonomous Region, Nanning 53002 I, People's Republic of China

*These authors contributed equally to this work.
Objective: The efficacy of surgery as the primary treatment modality for nasopharyngeal carcinoma (NPC) is yet to be clarified. Therefore, we aimed to explore the short- and longterm efficacy of surgery for early-stage NPC.

Methods: We retrospectively evaluated 341 patients diagnosed with early-stage NPC between September 2010 and December 2015. Among them, 58 patients underwent endoscopic nasopharyngectomy combined with chemoradiotherapy, whereas 283 patients underwent conventional chemoradiotherapy. The patients who underwent concurrent chemoradiotherapy or radiotherapy alone were matched to patients who underwent surgery in a 1:2 ratio using propensity score matching to analyze the clinical efficacy of each therapeutic modality. The primary endpoint was survival, and the secondary endpoints were tumor regression rate and reduction in Epstein-Barr virus (EBV)-DNA levels.

Results: After matching, 156 patients were enrolled (58 patients in the surgery group; 98 patients in the non-surgery group). The baseline data of the matched patients had good intergroup comparability (All $\mathrm{P}>0.05$ ). The surgery group had significantly higher 5-year overall survival (98.30\% vs. $91.70 \%$ ), disease-free survival (98.30\% vs. $81.40 \%$ ), and recurrencefree survival $(100.00 \%$ vs. $90.10 \%$ ) rates than did the non-surgery group (All $\mathrm{P}<0.05$ ). In total, 0 and 14 patients in the surgery and non-surgery groups, respectively, had residual cancer at the end of treatment $(\mathrm{P}=0.001)$. All patients in the surgery group tested negative for EBV-DNA, whereas two patients in the non-surgery group tested positive. The incidence of hematologic toxicity during treatment was similar between the two groups (All $\mathrm{P}>0.05$ ). Still, the incidence of severe oral mucositis was lower in the surgery group than in the nonsurgery group $(37.9 \%$ vs. $54.08 \%, \mathrm{P}=0.051)$.

Conclusion: Surgery can improve the clearance rate of $\mathrm{EB}$ virus and reduce tumor residue. Surgery may be a safe and effective treatment for early NPC.

Keywords: nasopharyngeal carcinoma, endoscopic surgery, radiotherapy, prognosis

\section{Introduction}

Radical endoscopic surgery is the primary treatment modality for early laryngeal cancer $^{1}$ and thyroid cancer. ${ }^{2}$ Endoscopic surgery not only enables complete tumor resection but also preserves organ functions. Nasopharyngeal carcinoma (NPC) is the most prevalent type of head and neck cancer in Southern China, ${ }^{3}$ with the most common pathological type being WHO type III, which is sensitive to radiotherapy. Most patients with NPC are diagnosed at the middle to the advanced stage of the disease due to the inaccessibility of the nasopharynx and the nonpalpable nature of early symptoms. Middle- to late-stage NPC is generally responsive to
Correspondence: Shen-Hong Qu Department of Otolaryngology \& Head and Neck, The People's Hospital of Guangxi Zhuang Autonomous Region, No. 6 Taoyuan Road, Nanning 53002I, People's Republic of China

Tel +86-77I-2I86580

Fax +86-77I-2186317

Email qshdoctor@163.com 
chemoradiotherapy. However, some patients experience treatment failure primarily due to residual disease, recurrence, distant metastasis, and nasopharyngeal hemorrhage. ${ }^{4,5}$ To ensure better local control rates, clinicians tend to increase the local radiation dose, which results in more radiotherapy-related complications.

The development of NPC screening modalities and advancements in imaging examinations have, in turn, increased the early detection rate of early-stage NPC in recent years. ${ }^{6}$ We previously found that endoscopic nasopharyngectomy yields better overall survival (OS) and lower incidence of xerostomia than conventional chemoradiotherapy. ${ }^{7}$ One study also showed that endoscopic nasopharyngectomy is not inferior to chemoradiotherapy with respect to recurrence and metastasis. ${ }^{8}$ Liu et al even reported residual tumors in a proportion of NPC patients who underwent chemoradiotherapy. ${ }^{9}$ Although surgery has been established as an effective modality for post-treatment residual or recurrent tumors, ${ }^{10}$ its efficacy as the initial treatment modality for NPC remains unclear. Further, the usefulness of neck dissection in NPC has rarely been studied. Thus, this study aimed to investigate the short- and long-term efficacy of endoscopic nasopharyngectomy combined with chemoradiotherapy with respect to the tumor regression rate and prognosis in patients with early NPC.

\section{Data and Methods}

\section{Study Design and Patients}

Data for the patients with NPC were retrieved from the database of The People's Hospital of Guangxi Zhuang Autonomous Region (Nanning, China). This study was approved by our institutional ethical committee (NO.20080301). We evaluated 341 patients diagnosed with early-stage NPC between September 2010 and December 2015. The inclusion criteria were: (1) treatmentnaïve pathologically diagnosed early NPC (stage I and II); (2) Karnofsky score $>80$ points; (3) no distant metastasis. Exclusion criteria: (1) T1 patients with oropharynx invasion; (2) T2 patients with internal carotid artery involvement or posterior parapharyngeal space invasion, or patients with parapharyngeal lymph node enlargement. In total, 341 NPC patients were included. Among them, 58 underwent endoscopic nasopharyngectomy with or without neck dissection, whereas 283 underwent chemoradiotherapy. All patients were staged according to the
Union for International Cancer Control NPC staging system (7th Edition, 2010).

\section{Treatment}

\section{Surgery}

The detailed procedures for administrating endoscopic nasopharyngectomy were performed as previously reported. ${ }^{7}$ All patients were administered general anesthesia before the surgery. Nasopharyngeal tumors were resected using a nasal electromotor, a plasma scalpel guided by a nasal endoscope. The tumor margins after primary resection were evaluated using magnetic resonance imaging (MRI) of the nasopharynx and skull base as well as intraoperative observations. For N1 patients, functional neck dissection was performed concurrently.

\section{Radiotherapy}

All patients received radiotherapy. For conventional radiotherapy, total radiation dose was 70 76Gy for nasopharyngeal lesions and 60 70Gy for cervical lesions in the non-surgery group, while total radiation dose was 60 64 Gy for nasopharyngeal lesions and 60 64 Gy for cervical lesions in the surgery group. For intensity-modulated radiation therapy (IMRT), the prescribed dose was 69 72Gy for nasopharyngeal lesions and cervical lesions in the non-surgery group, while the prescribed dose was 59.4 63.8Gy for nasopharyngeal lesions and cervical lesions in the surgery group.

\section{Chemotherapy}

In general, the patients with stage II disease (T2N0, T1N1 and T2N1) were recommended to receive concurrent chemotherapy. The chemotherapy programs were: (1) Nedaplatin $80 \mathrm{mg} / \mathrm{m}^{2}$ was administered via intravenous drip infusion on day 1 , followed by a 120 -h continuous infusion of $2000 \mathrm{mg} / \mathrm{m}^{2}$ 5-FU every four weeks for $2-3$ cycles; or (2) Cisplatin $30 \mathrm{mg} / \mathrm{m}^{2}$ was administered via intravenous drip infusion on day $1-3$, followed by a 120 $\mathrm{h}$ continuous infusion of $2000 \mathrm{mg} / \mathrm{m}^{2}$ 5-FU every four weeks for 2-3 cycles.

\section{Detection of Blood Cells}

The blood tests for hemoglobin level, neutrophil counts, platelet counts, and white blood cell (WBC) counts were obtained before, during, and after treatment was carried out. Myelosuppression was assessed per the criteria for evaluating toxicity and side effects of drugs in the 
Common Terminology Criteria for Adverse Events (Version 4.03) issued by the US National Cancer Institute.

\section{Evaluation of Tumor Regression Rate}

All patients underwent contrast-enhanced MRI of the nasopharynx and skull base before and at the end of treatment. The tumor regression rate was evaluated based on the Response Evaluation Criteria in Solid Tumors (version 1.1). ${ }^{11}$

\section{Evaluation of Oral Mucositis}

Acute reactions in the oral and pharyngeal mucosa were evaluated according to the Common Terminology Criteria for Adverse Events (Version 4.03). Grade $\geq 3$ mucosal reactions were classified as severe mucositis, whereas grade 1 or 2 reactions were mild mucositis.

\section{Follow-Up}

After completing treatment, patients were subsequently followed up every 3 months during the first years, every
6 months during the second year, and annually from the third year onwards.

The OS was defined as the period from the diagnosis of NPC to the date of death from any cause or the censoring of patients at the last follow-up. Disease-free survival (DFS) was defined as the period from the diagnosis to the date of disease recurrence, metastasis, or death. Relapse-free survival (RFS) was defined as the interval from the diagnosis to first recurrence or final follow-up. Distant metastasis-free survival (DMFS) was defined as the time from the diagnosis to first distant metastasis or final follow-up.

\section{Statistical Analysis}

The primary endpoint was survival, and the secondary endpoints were tumor regression rate and the reduction in Epstein-Barr virus (EBV-DNA) levels. All statistical analyses were performed using the $\mathrm{R}$ statistical software (ver.3.6.1). Propensity score matching of $1: 2$

Table I Baseline Characteristics of 34I Patients

\begin{tabular}{|c|c|c|c|c|c|}
\hline Characteristics & All Patients $(n=34 I)$ & Non-Surgery $(n=283)$ & Surgery $(n=58)$ & $\chi^{2} / \mathrm{t}$ & $P$ value \\
\hline Age & $47.26(10.68)$ & $47.63(10.77)$ & $45.45(10.13)$ & 1.42 & 0.158 \\
\hline \multicolumn{6}{|l|}{ Sex } \\
\hline Male & $230(67.45 \%)$ & 183 (64.66\%) & 47 (81.03\%) & 5.88 & 0.025 \\
\hline Female & III (32.55\%) & $100(35.34 \%)$ & II (I8.97\%) & & \\
\hline \multicolumn{6}{|l|}{ T stage } \\
\hline I & $90(26.39 \%)$ & 56 (19.79\%) & $34(58.62 \%)$ & 37.36 & $<0.001$ \\
\hline 2 & 251 (73.61\%) & 227 (80.21\%) & 24 (4I.38\%) & & \\
\hline \multicolumn{6}{|l|}{$\mathrm{N}$ stage } \\
\hline 0 & $174(51.03 \%)$ & $|3|(46.29 \%)$ & 43 (74.14\%) & 14.94 & $<0.001$ \\
\hline I & 167 (48.97\%) & 152 (53.7I\%) & 15 (25.86\%) & & \\
\hline \multicolumn{6}{|l|}{ Clinical stage } \\
\hline I & 58 (17.01\%) & 33 (11.66\%) & $25(43.10 \%)$ & 33.71 & $<0.001$ \\
\hline II & $283(82.99 \%)$ & $250(88.34 \%)$ & $33(56.90 \%)$ & & \\
\hline \multicolumn{6}{|l|}{ Radiotherapy } \\
\hline $\mathrm{IMRT}^{\mathrm{a}}$ & $232(68.04 \%)$ & 194 (68.55\%) & 38 (65.52\%) & 0.20 & 0.774 \\
\hline $2 \mathrm{DRT} T^{\mathrm{b}}$ & 109 (31.96\%) & 89 (31.45\%) & $20(34.48 \%)$ & & \\
\hline \multicolumn{6}{|c|}{ Concurrent Chemotherapy } \\
\hline Without & 45 (I3.20\%) & 39 (13.78\%) & $6(10.34 \%)$ & 0.50 & 0.546 \\
\hline With & $296(86.80 \%)$ & $244(86.22 \%)$ & $52(89.66 \%)$ & & \\
\hline \multicolumn{6}{|l|}{ Residual_position } \\
\hline No & $289(84.75 \%)$ & $23 \mathrm{I}(8 \mathrm{I} .63 \%)$ & 58 (100.00\%) & 12.57 & 0.007 \\
\hline $\mathrm{NP}^{\mathrm{c}}$ & $29(8.50 \%)$ & 29 (10.25\%) & $0(0.00 \%)$ & & \\
\hline $\mathrm{LN}^{\mathrm{d}}$ & 22 (6.45\%) & $22(7.77 \%)$ & $0(0.00 \%)$ & & \\
\hline NP\&LN & I (0.29\%) & I (0.35\%) & $0(0.00 \%)$ & & \\
\hline
\end{tabular}

Notes: ${ }^{a}$ Intensity modulated radiotherapy; ${ }^{b}$-dimensional radiotherapy; ${ }^{\mathrm{C}}$ Nasopharynx; ${ }^{\mathrm{d}}$ Cervical lymph nodes. Bold formatting indicates statistically significant. 
A
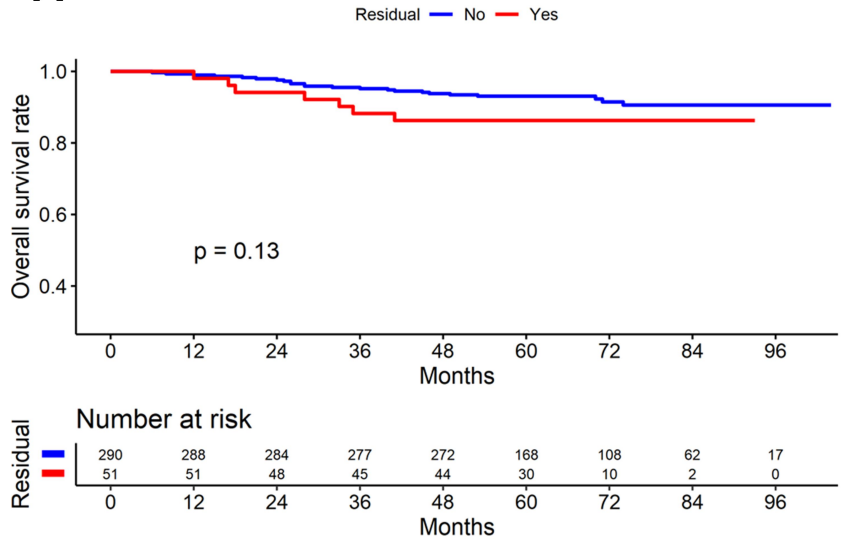

B
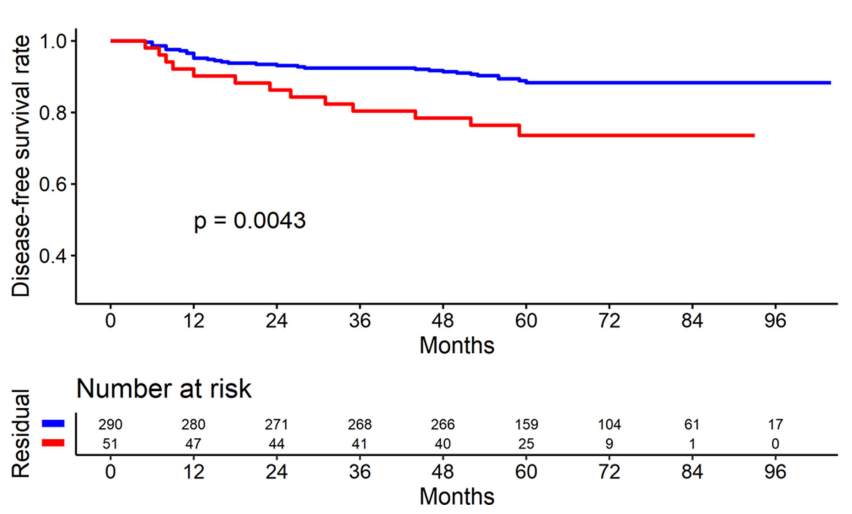
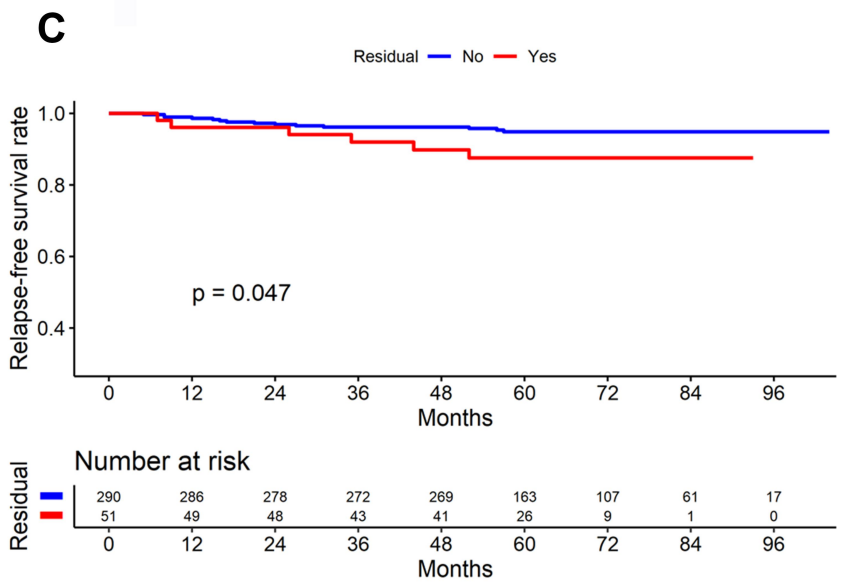

D

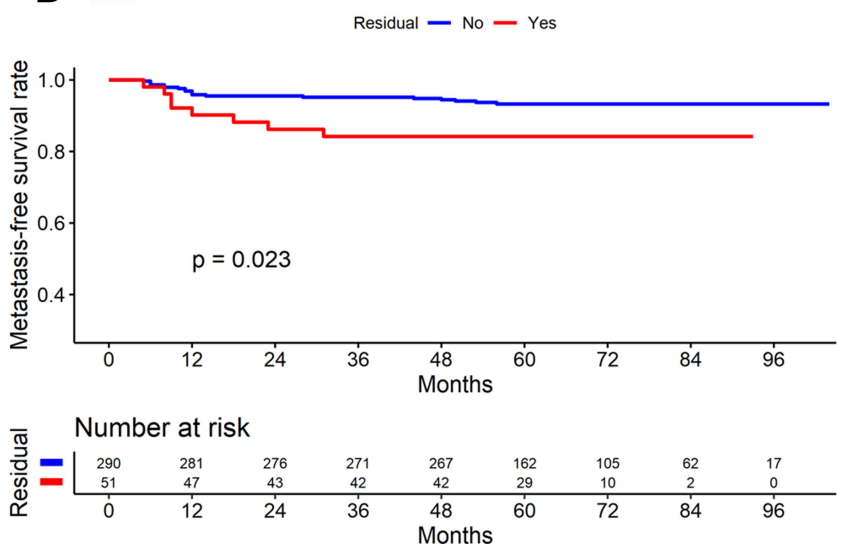

Figure I Comparison of survival curves between residual and non-residual group in patients with early-stage nasopharyngeal carcinoma $(\mathrm{n}=34 \mathrm{I})((\mathbf{A})$ Overall survival; $(\mathbf{B})$ Disease-free survival; (C) Relapse-free survival; (D) Distant metastasis-free survival).

scheme was applied to develop comparable cohorts of patients with surgery and without surgery. Count data were compared using the $\chi 2$ test, whereas measurement data were analyzed using the $t$-test or analysis of variance. Non-normally distributed measurement data were compared using the rank-sum test. Survival curves were plotted using the Kaplan-Meier method for univariate survival analysis and then analyzed using the Log rank test. Multivariate analysis was performed using the Cox proportionalhazards model. $\mathrm{P}<0.05$ was considered statistically significant.

\section{Results}

\section{Patient Characteristics}

Sex, $\mathrm{T}$ stage, $\mathrm{N}$ stage, clinical stage, and position of residual tumors were significantly different between the surgery and the non-surgery groups (All $\mathrm{P}<0.05$ ), as shown in Table 1 . In total, 51 of the 341 patients had residual tumors at the end of treatment (28 patients with nasopharyngeal residue; 22 patients, cervical residue; and one patient, nasopharyngeal plus cervical residues). There were 7 and 44 patients with T1 and T2 disease, respectively, who had residual tumors. At the end of treatment, the residual group had lower disease-free survival (DFS), recurrence-free survival (RFS), and distant metastasis-free survival (DMFS) rates than did the non-residual group (All $\mathrm{P}<0.05$ ), but there was no significant difference in their OS rates $(\mathrm{P}>0.05)$ (Figure 1).

\section{Matching results}

After matching, 156 patients were included in the analysis (58 patients in the surgery group; 98 patients in the non-surgery group). There were no significant differences in age, sex, $\mathrm{T}$ stage, $\mathrm{N}$ stage, clinical stage, and radiotherapy modality (All $\mathrm{P}>0.05$ ) between the two groups (Table 2). 
Table 2 Baseline Characteristics of Patients After Propensity Score Matching

\begin{tabular}{|c|c|c|c|c|c|}
\hline Characteristics & All Patients $(n=156)$ & Non-Surgery $(n=98)$ & Surgery $(n=58)$ & $\chi^{2} / \mathrm{t}$ & $P$ value \\
\hline Age & 47.06 (10.69) & 48.01 (10.95) & $45.45(10.13)$ & 1.45 & 0.149 \\
\hline \multicolumn{6}{|l|}{ Sex } \\
\hline Male & $123(78.85 \%)$ & 76 (77.55\%) & 47 (81.03\%) & 0.27 & 0.709 \\
\hline Female & $33(21.15 \%)$ & $22(22.45 \%)$ & II (I8.97\%) & & \\
\hline \multicolumn{6}{|l|}{ T stage } \\
\hline I & $84(53.85 \%)$ & $50(51.02 \%)$ & $34(58.62 \%)$ & 0.85 & 0.426 \\
\hline 2 & $72(46.15 \%)$ & 48 (48.98\%) & 24 (4I.38\%) & & \\
\hline \multicolumn{6}{|l|}{$N$ stage } \\
\hline 0 & III (7I.15\%) & 68 (69.39\%) & $43(74.14 \%)$ & 0.40 & 0.601 \\
\hline 1 & $45(28.85 \%)$ & $30(30.61 \%)$ & $15(25.86 \%)$ & & \\
\hline \multicolumn{6}{|l|}{ Clinical stage } \\
\hline I & 57 (36.54\%) & $32(32.65 \%)$ & $25(43.10 \%)$ & 1.72 & 0.253 \\
\hline II & $99(63.46 \%)$ & $66(67.35 \%)$ & $33(56.90 \%)$ & & \\
\hline \multicolumn{6}{|l|}{ Radiotherapy } \\
\hline $\mathrm{IMRT}^{\mathrm{a}}$ & II 3 (72.44\%) & 75 (76.53\%) & 38 (65.52\%) & 2.21 & 0.163 \\
\hline $2 \mathrm{DRT} T^{\mathrm{b}}$ & $43(27.56 \%)$ & $23(23.47 \%)$ & $20(34.48 \%)$ & & \\
\hline \multicolumn{6}{|c|}{ Concurrent Chemotherapy } \\
\hline No & $27(17.31)$ & $21(21.43)$ & $6(10.34)$ & 3.13 & 0.093 \\
\hline Yes & $129(82.69)$ & 77 (78.57) & $52(89.66)$ & & \\
\hline \multicolumn{6}{|l|}{ Residualposition } \\
\hline No & $|4|(90.38 \%)$ & 84 (85.7।\%) & $58(100.00 \%)$ & 9.10 & 0.014 \\
\hline$N P^{c}$ & II (7.05\%) & $10(10.20 \%)$ & $0(0.00 \%)$ & & \\
\hline $\mathrm{LN}^{\mathrm{d}}$ & $3(1.92 \%)$ & 3 (3.06\%) & $0(0.00 \%)$ & & \\
\hline NP\&LN & I (0.64\%) & I (I.025) & $0(0.00 \%)$ & & \\
\hline
\end{tabular}

Note: Bold formatting indicates statistically significant.

Abbreviations: ${ }^{a}$ Intensity modulated radiotherapy; ${ }^{\text {}} 2$-dimensional radiotherapy; ${ }^{c}$ Nasopharynx; ${ }^{d}$ Cervical lymph nodes.

Table 3 Univariate Survival Analysis of 156 Patients with Nasopharyngeal Carcinoma

\begin{tabular}{|l|l|l|l|l|l|l|l|l|}
\hline \multirow{2}{*}{ Variable } & \multicolumn{2}{l}{ OS } & \multicolumn{2}{l|}{ DFS } & \multicolumn{2}{l|}{ RFS } & \multicolumn{2}{l|}{ DMFS } \\
\cline { 2 - 9 } & $\chi^{2}$ & $\boldsymbol{P}$ value & $\chi^{2}$ & $\boldsymbol{P}$ value & $\chi^{2}$ & $\boldsymbol{P}$ value & $\chi^{2}$ & $\boldsymbol{P}$ value \\
\hline Age group & 4.37 & $\mathbf{0 . 0 3 7}$ & 6.25 & $\mathbf{0 . 0 1 2}$ & 6.49 & $\mathbf{0 . 0 1 1}$ & 1.45 & 0.229 \\
Sex & 2.91 & 0.088 & 2.52 & 0.112 & 2.50 & 0.114 & 0.61 & 0.436 \\
T stage & 0.08 & 0.783 & 0.30 & 0.586 & 0.02 & 0.894 & 0.31 & 0.581 \\
N stage & 5.30 & $\mathbf{0 . 0 2 1}$ & 3.68 & $\mathbf{0 . 0 5 5}$ & 0.16 & 0.689 & 7.18 & $\mathbf{0 . 0 0 7}$ \\
Clinical stage & 2.27 & 0.132 & 1.47 & 0.225 & 0.06 & 0.807 & 2.65 & 0.104 \\
RT technique & 0.93 & 0.334 & 0.28 & 0.595 & 0.10 & 0.750 & 1.19 & 0.276 \\
Endoscopic surgery & 5.43 & $\mathbf{0 . 0 2 0}$ & 8.31 & $\mathbf{0 . 0 0 4}$ & 5.76 & $\mathbf{0 . 0 1 6}$ & 2.87 & $\mathbf{0 . 0 9 0}$ \\
\hline
\end{tabular}

Note: Bold formatting indicates statistically significant.

Abbreviations: OS, overall survival; DFS, disease-free survival; RFS, relapse-free survival; DMFS, distant metastasis-free survival; RT, radiotherapy.

\section{Survival Analysis}

The median follow-up was 63 months (29-104 months) with the following stats: 12 patients died, 8 patients experienced recurrence, and 8 patients developed distant metastases, 1 patient developed recurrence and distant metastases. In total,
0 and 14 patients in the surgery and the non-surgery groups, respectively, had a residual tumor at the end of the treatment $(\mathrm{P}=0.001)$. The surgery group had significantly higher 5-year OS $(98.30 \%$ vs. $91.70 \%)$, DFS $(98.30 \%$ vs. $81.40 \%)$, RFS ( $100.00 \%$ vs. $90.10 \%)$, and DMFS $(98.30 \%$ vs. $91.30 \%)$ rates 

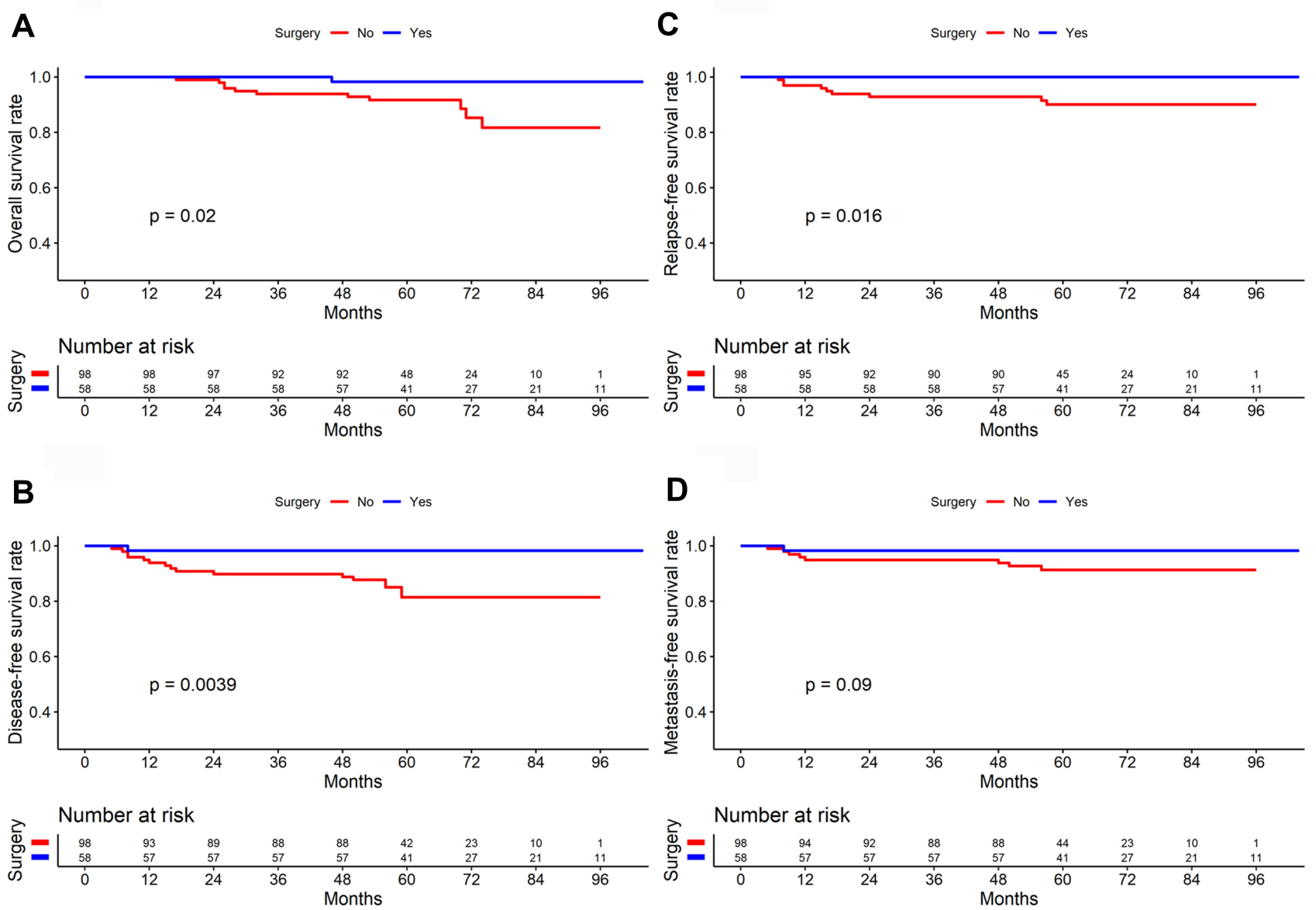

Figure 2 Comparison of survival curves between surgery and non-surgery group in patients with early-stage nasopharyngeal carcinoma $(n=I 56)((\mathbf{A})$ Overall survival; $(\mathbf{B})$ Disease-free survival; (C) Relapse-free survival; (D) Distant metastasis-free survival).

than did the non-surgery group $(\mathrm{P}=0.020,0.004,0.016$, and 0.090 , respectively, Table 3 and Figure 2). Multivariate analysis showed that surgery is an independent variable influencing DFS (Figure 3).

\section{Subgroup Analysis}

In the survival analysis of 57 patients with stage I NPC, the results showed no significant difference in OS, DFS, RFS, and DMFS between the surgery and non-surgery groups (All $\mathrm{P}>0.05$ ). In the survival analysis of 99 patients with stage II NPC, the surgery group had higher OS, DFS, and RFS rates than did the non-surgery group $(\mathrm{P}=0.079$, 0.037, and 0.077, respectively, Figure 4). Among stage II patients with lymph node metastasis, the neck dissection group $(\mathrm{n}=14)$ had higher 5-year OS $(92.90 \%$ vs. $87.10 \%)$, DFS (92.90\% vs. $75.90 \%$ ), RFS (100.00\% vs. 90.30\%), and DMFS (92.90\% vs. $82.00 \%)$ than did the nondissection group $(n=31)$, but the differences were not significant (All $\mathrm{P}>0.05$, Figure 5). In 4 of the 14 patients who underwent endoscopic nasopharyngectomy combined with neck dissection, the postoperative pathological analysis indicated by the absence of metastatic carcinoma in the cervical lymph nodes. The representative cases are presented in Figure 6.

\section{Changes in EBV-DNA}

The average pretreatment EBV-DNA level was $0.57 \log 10$ copies $/ \mathrm{mL}$ for the surgery group and $0.58 \log 10$ copies $/ \mathrm{mL}$ for the non-surgery group $(\mathrm{P}=0.967)$. At the end of the treatment, all patients in the surgery group tested negative for EBV-DNA, whereas two patients in the non-surgery group tested positive for EBV-DNA.

\section{Inter-Group Comparison of Radiation Dose and Toxic Effects}

The median nasopharyngeal radiation dose was $60 \mathrm{~Gy}$ for the surgery group and $70 \mathrm{~Gy}$ for the non-surgery group, with significant difference $(\mathrm{P}<0.001)$. The incidence of 
A

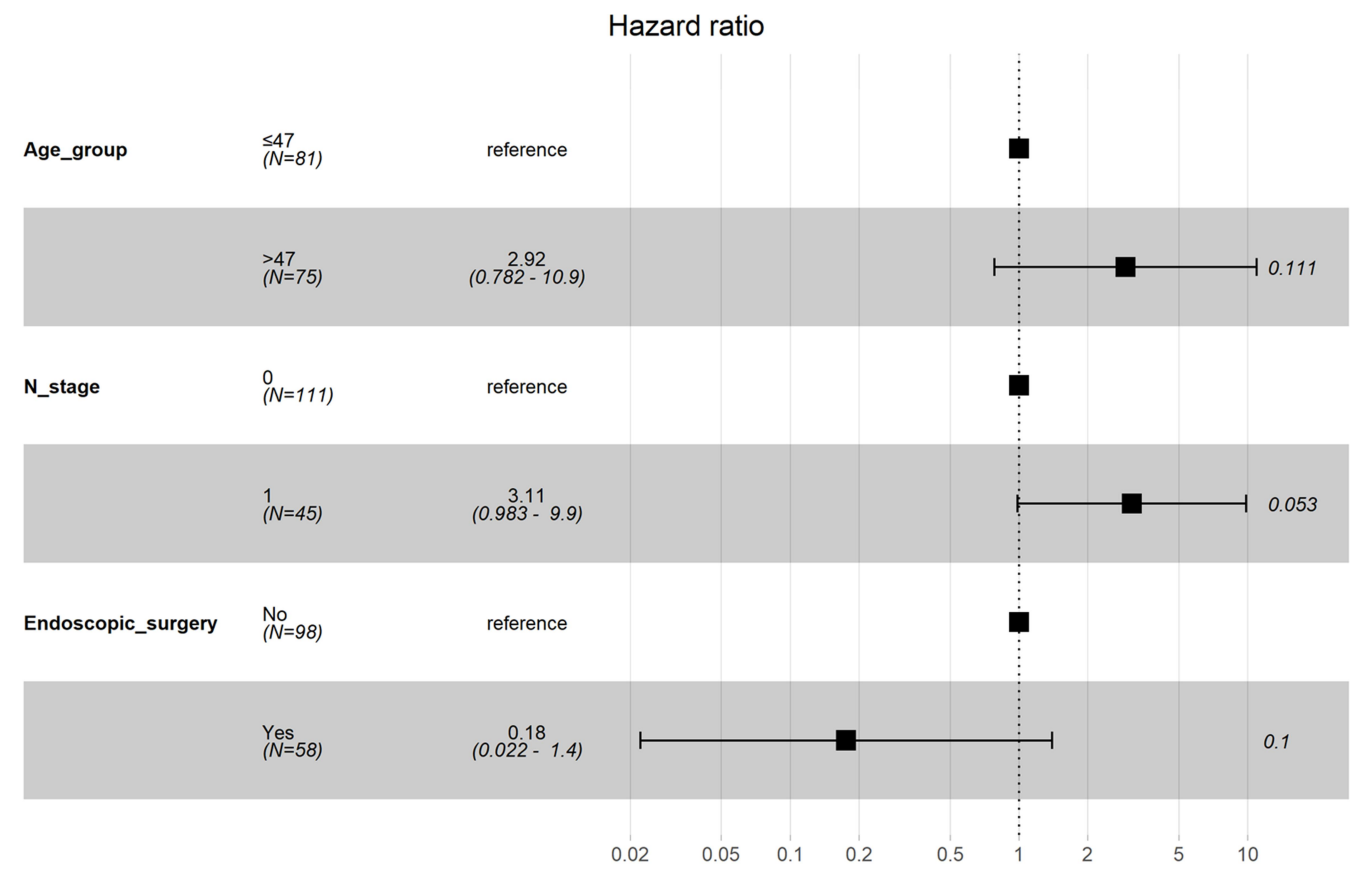

B

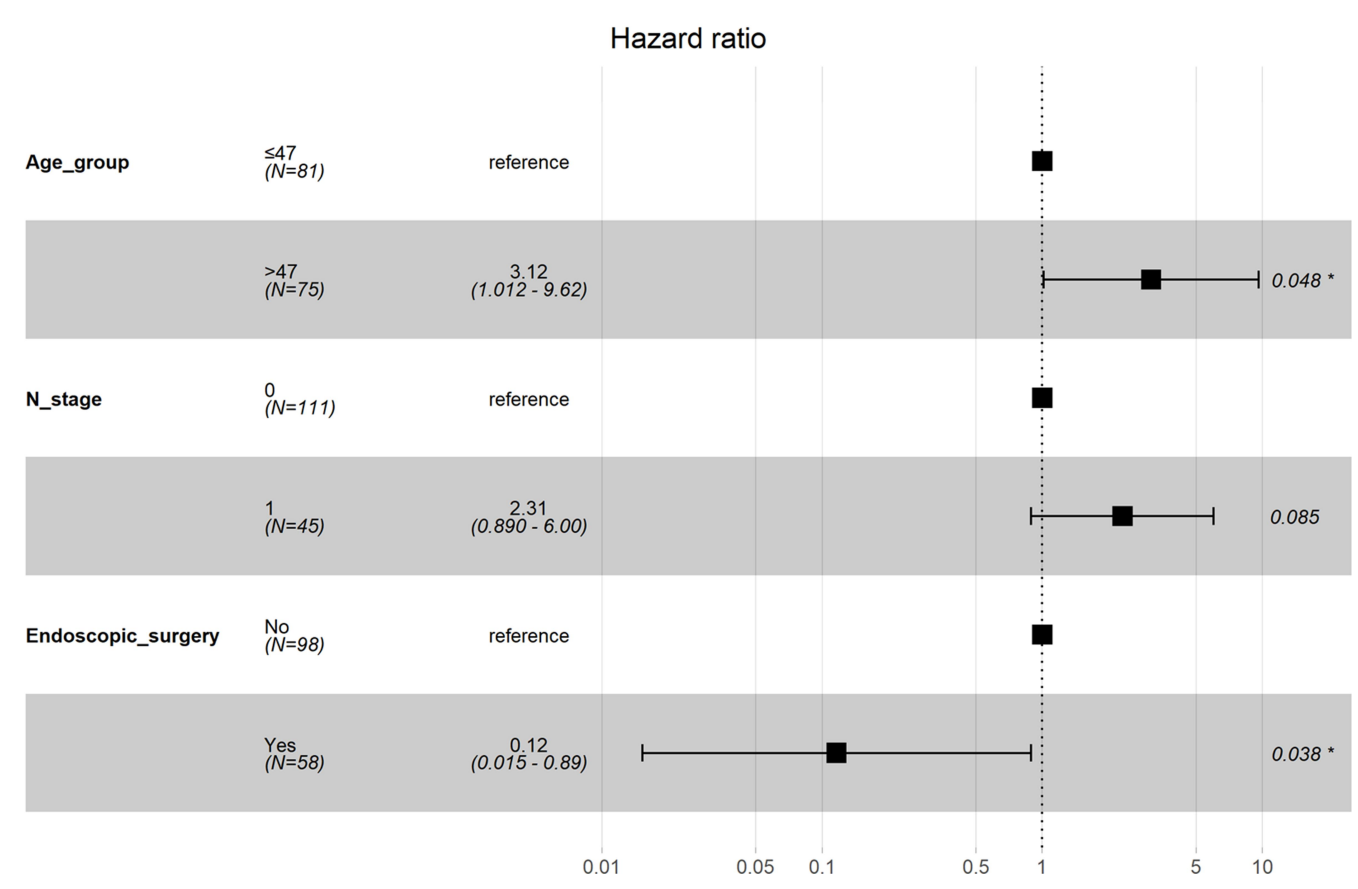

Figure 3 Forest plots depicting the multivariate association of clinicopathological characteristics with overall survival (A) and disease-free survival (B). *Indicates statistically significant.

hematologic toxicities during treatment was similar between the two groups (Figure 7). The incidence of severe oral mucositis throughout treatment was significantly different between the surgery group and the nonsurgery group $(37.9 \%$ vs. $54.08 \%, \mathrm{P}=0.051)$. The mean weight loss at the end of treatment was $6.09 \pm 3.72 \mathrm{~kg}$ in the surgery group and $5.22 \pm 2.80 \mathrm{~kg}$ in the non-surgery group, with no significant difference $(\mathrm{P}=0.098)$, as shown in Figure 8.

\section{Discussion}

The efficacy of surgery as the primary treatment modality for NPC is yet to be clarified. This study found that surgery combined with chemoradiotherapy can 

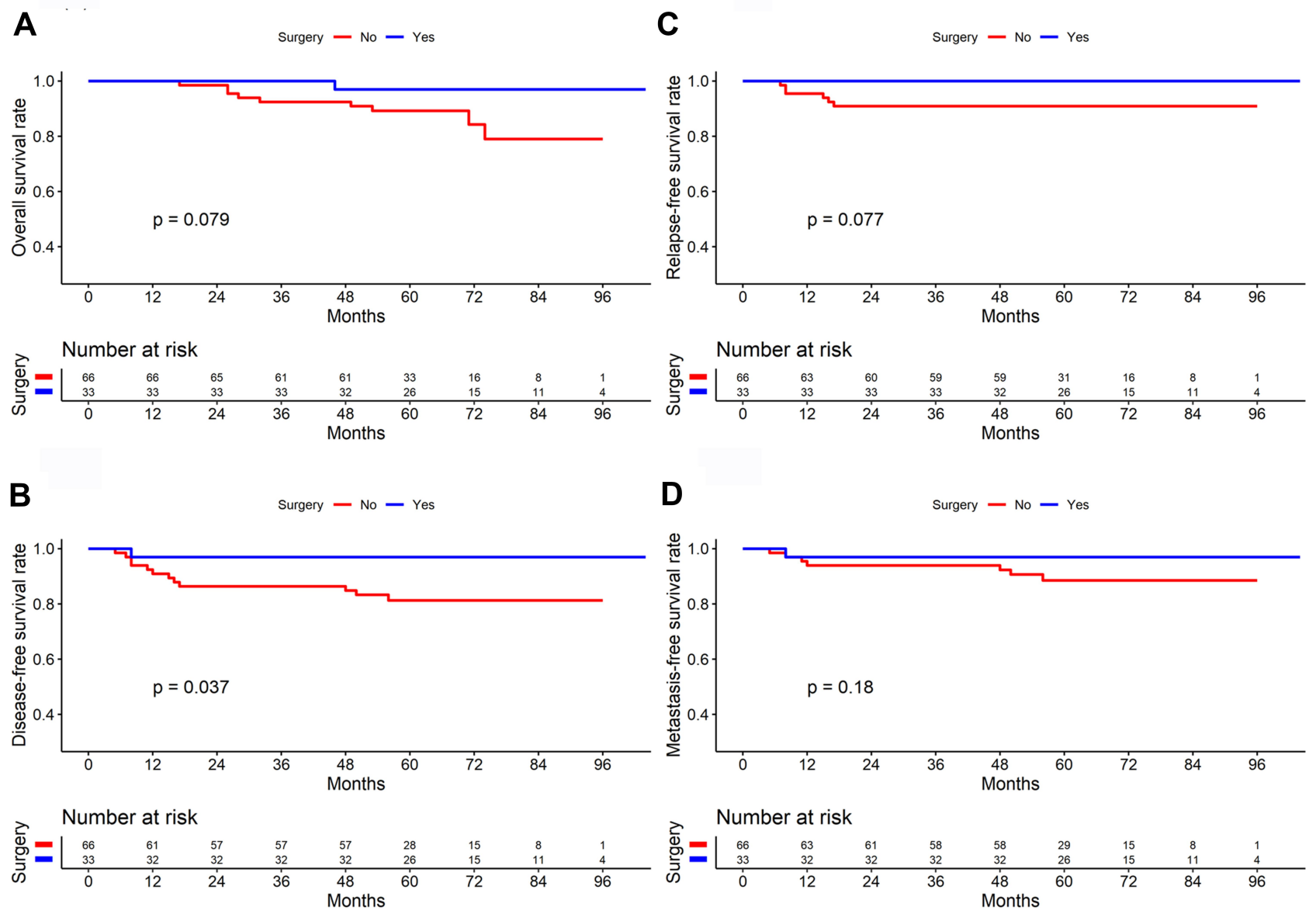

Figure 4 Comparison of survival curves between surgery and non-surgery group in patients with stage II nasopharyngeal carcinoma $(\mathrm{n}=99)((\mathbf{A})$ Overall survival; $(\mathbf{B})$ Disease-free survival; (C) Relapse-free survival; (D) Distant metastasis-free survival).

improve survival in NPC patients, particularly those with stage II disease. The OS and DFS rates of the surgery group were higher than those of the nonsurgery group even after propensity score matching. Multivariate Cox regression analysis also showed that surgery is an independent factor influencing the DFS of NPC patients.

Residual tumors after treatment are found in approximately $7 \%$ to $13 \%$ of NPC patients; ${ }^{12}$ similar finding was obtained in the current study (14.9\%). However, unlike previous studies, we evaluated the tumor regression rate at the end of treatment. The common types of residual tumors include local (nasopharyngeal) and regional (cervical) residual disease, with the latter occurring more frequently than the former at the end of treatment. ${ }^{13}$ In this study, nasopharyngeal residues $(n=28)$ were slightly more common than cervical residues $(n=22)$, but both of these occurred only in the chemoradiotherapy group. No tumor residue was found in the surgery group. Although biopsy is widely recognized as the gold standard for diagnosing residual NPC, tumor tissues are difficult to extract through biopsy because $69.4 \%$ of lesions occur outside the nasopharynx. ${ }^{14}$ Thus, currently, residual tumors are primarily diagnosed using contrast-enhanced MRI. ${ }^{13,15}$ However, the nasopharyngeal biopsy is an ideal diagnostic modality for residual lesions protruding into the nasal cavity. Biopsied tissues can also be subjected to immunohistochemistry for several markers, such as the Ki-67 labeling index, to understand tumor proliferation. ${ }^{16}$ Positron emission tomography-computed tomography (PET-CT) is more accurate than MRI for evaluating local lesions, but also more expensive. ${ }^{17}$ Existing literature on the prognostic impact of residual NPC is relatively limited and inconclusive. One study found no significant difference in survival rates between patients with and without residual disease after NPC treatment, and therefore, 
A
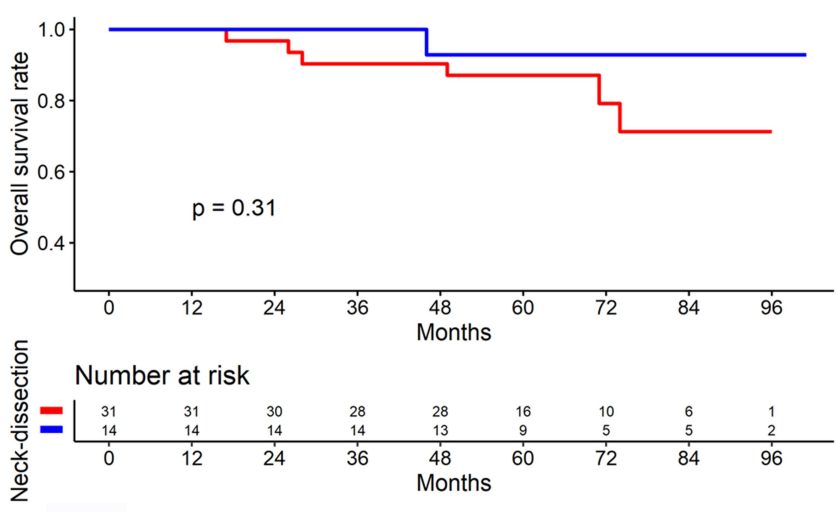

B
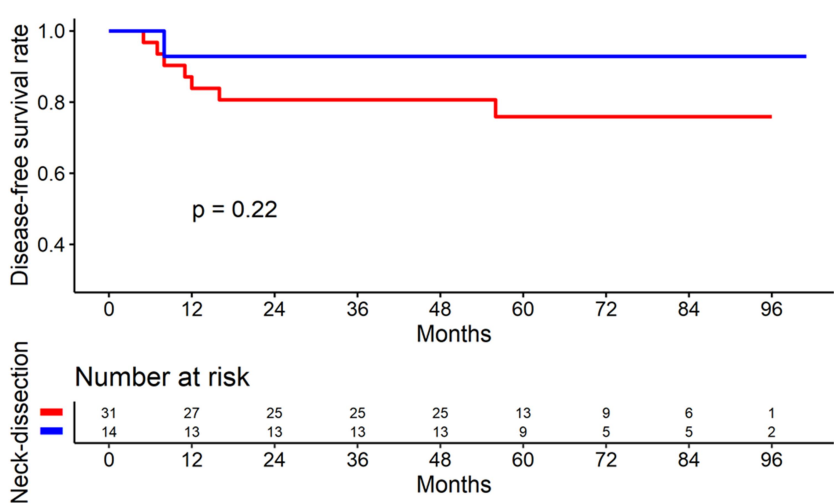

C
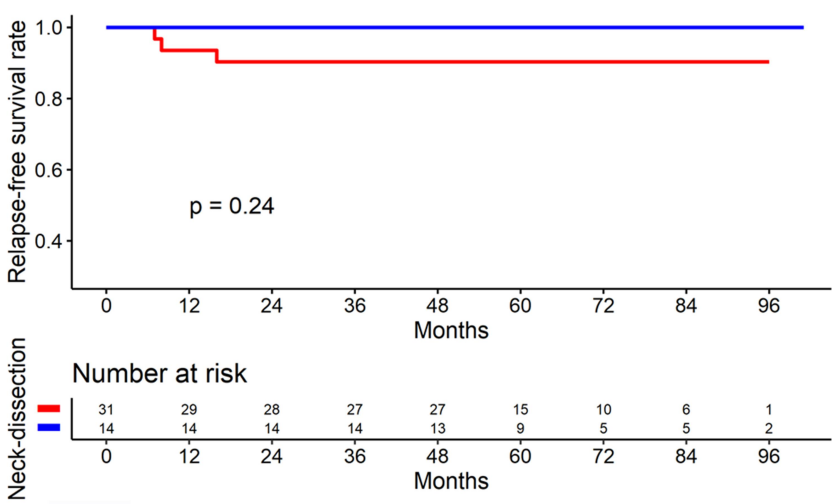

D

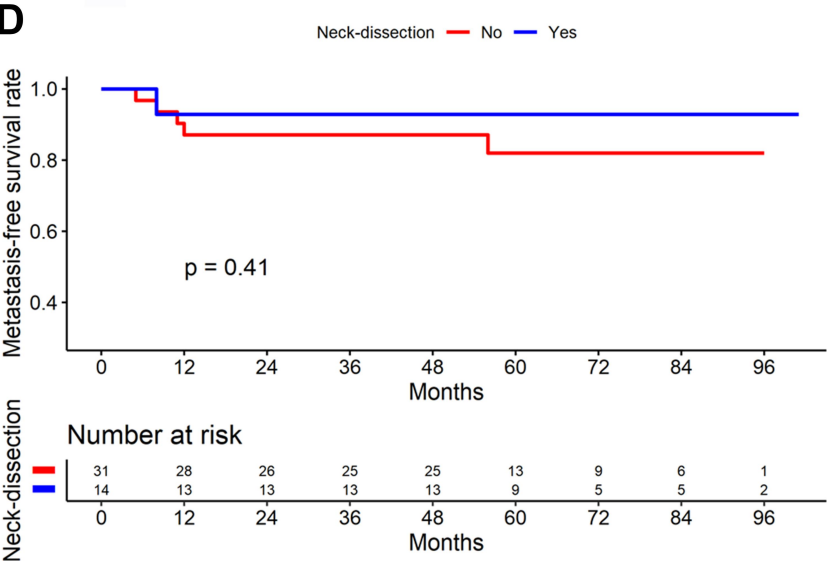

Figure 5 Comparison of survival curves between neck dissection and non-neck dissection in patients with TI-2NI nasopharyngeal carcinoma ( $\mathrm{n}=45)((\mathbf{A})$ Overall survival; (B) Disease-free survival; (C) Relapse-free survival; (D) Distant metastasis-free survival).

recommended follow-up observation for these patients. ${ }^{18}$ In contrast, another study reported that the group with the residual disease should be actively treated as this group has lower survival rates than the group with no residual disease. ${ }^{19}$ Similarly, the group with residual disease in this study also had lower DFS, RFS, and DMFS than the group with no residual disease. $\mathrm{T}$ staging has been previously found to be the main influencing factor of local failure. ${ }^{20} \mathrm{We}$ also found a higher rate of residual disease of $17.5 \%$ in $\mathrm{T} 2$ patients, whereas it was only $7.8 \%$ in $\mathrm{T} 1$ patients. This implied that the risk of residual tumor is positively correlated with the tumor size.

The EBV-DNA level at three months after treatment has been reported to be associated with tumor residue, ${ }^{13}$ and this association could be possible because NPC cells are a possible source of plasma EBV-DNA. Tumor residue, local recurrence, and distant metastasis are likely to occur in patients with detectable EBV-DNA even after treatment. ${ }^{21}$ In this study, all patients in the surgery group tested negative for EBV-DNA at the end of treatment, whereas two patients in the chemoradiotherapy group remained positive for EBV-DNA. This was probably because the surgical resection removed the nasopharyngeal and cervical lesions, and consequently, reduced the main sources of $\mathrm{EBV}^{22}$ Wang et al also reported that the EBV clearance rate is an independent risk factor influencing NPC prognosis. ${ }^{23}$

We previously found a higher 3-year OS rate in early NPC patients undergoing surgery than in patients undergoing chemoradiotherapy $(98.44 \%$ vs. $91.98 \%)$, whereas 


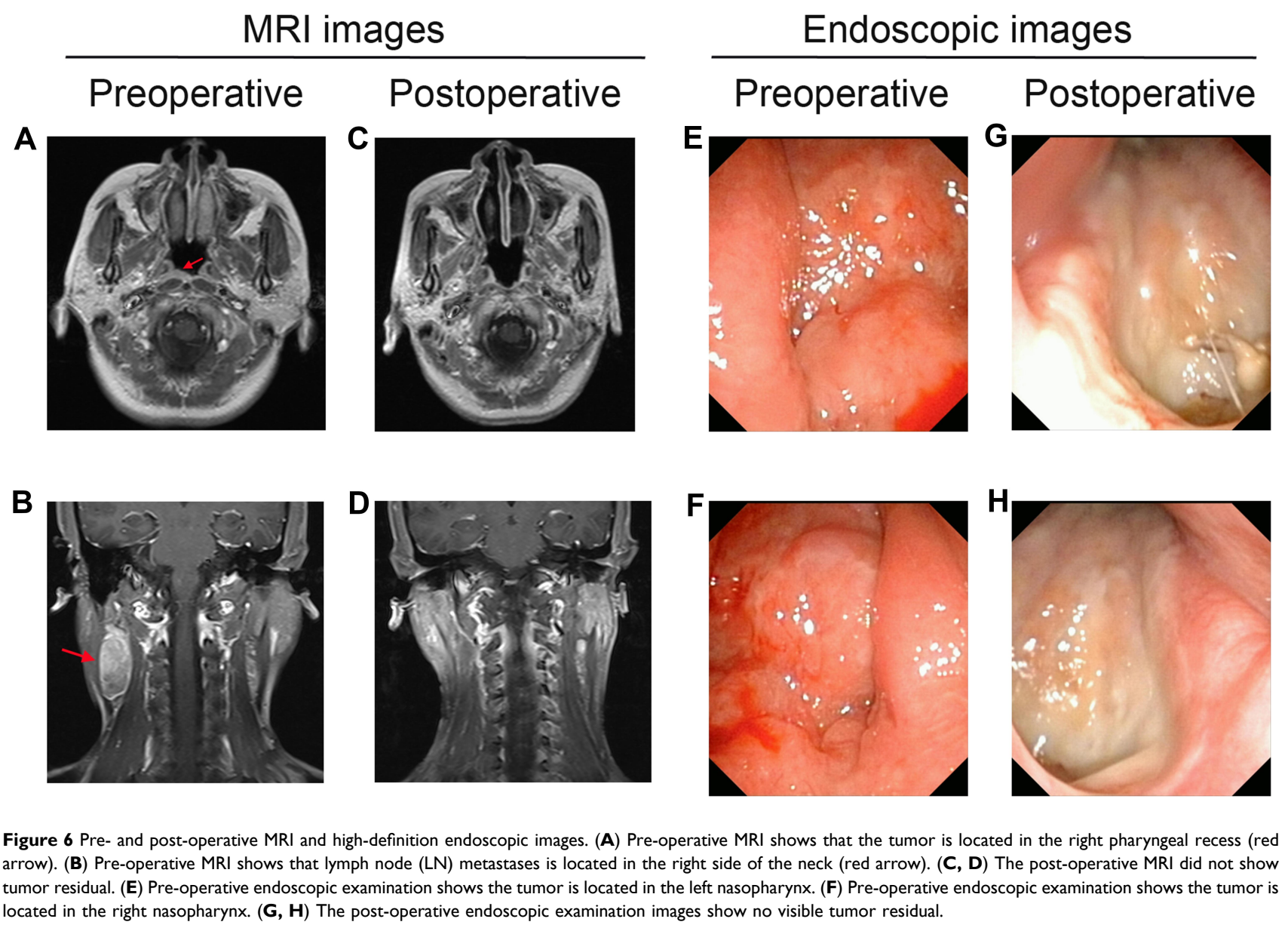

tumor residual. (E) Pre-operative endoscopic examination shows the tumor is located in the left nasopharynx. (F) Pre-operative endoscopic examination shows the tumor is located in the right nasopharynx. (G, H) The post-operative endoscopic examination images show no visible tumor residual.

there was no significant difference in DFS. ${ }^{7}$ Based on these findings, we extended the follow-up period in the current study and similarly found better OS and DFS rates in the surgery group than in the non-surgery group. However, in subgroup analysis, the current study found that the efficacy of surgery is similar to that of radiotherapy among stage I NPC patients, in line with another study, except that the previous study evaluated ten newly diagnosed localized stage I NPC patients, and the surgery group did not undergo postoperative chemoradiotherapy. ${ }^{8}$ On contrast, among the stage II patients, surgery was superior to chemoradiotherapy with respect to the DFS. Further analysis of the N1 patients showed that 14 of the 15 patients who underwent endoscopic surgery also underwent functional neck dissection. The results of the survival analysis showed better survival in those who underwent dissection, but the difference was not statistically significant. This could be because of the limited number of cases.
A previous study showed that cells from lymph node metastases could form new colonies of metastatic cancer cells in the lungs or other organs. ${ }^{24}$ Hence, preventing or reducing lymph node metastases can lower the risk of tumor metastasis. Wong et al suggested that surgical treatment is more appropriate for locally advanced NPC without distant metastasis, ${ }^{25}$ because the ratio of hypoxic cells increases with the size of the tumor, which significantly diminishes the radiation sensitivity of the tumor cells. These indicated that the promotion in DFS for NPC patients treated with surgery may be associated with removing radioresistant disease as compared with radiotherapy.

The incidence of severe oral mucositis in the current study was lower in the surgery group than in the non-surgery group, possibly because the former was exposed to a lower radiation dose. As the mucosa is an early responding tissue, the mucosa is associated with the overall radiation dose. The oral and 

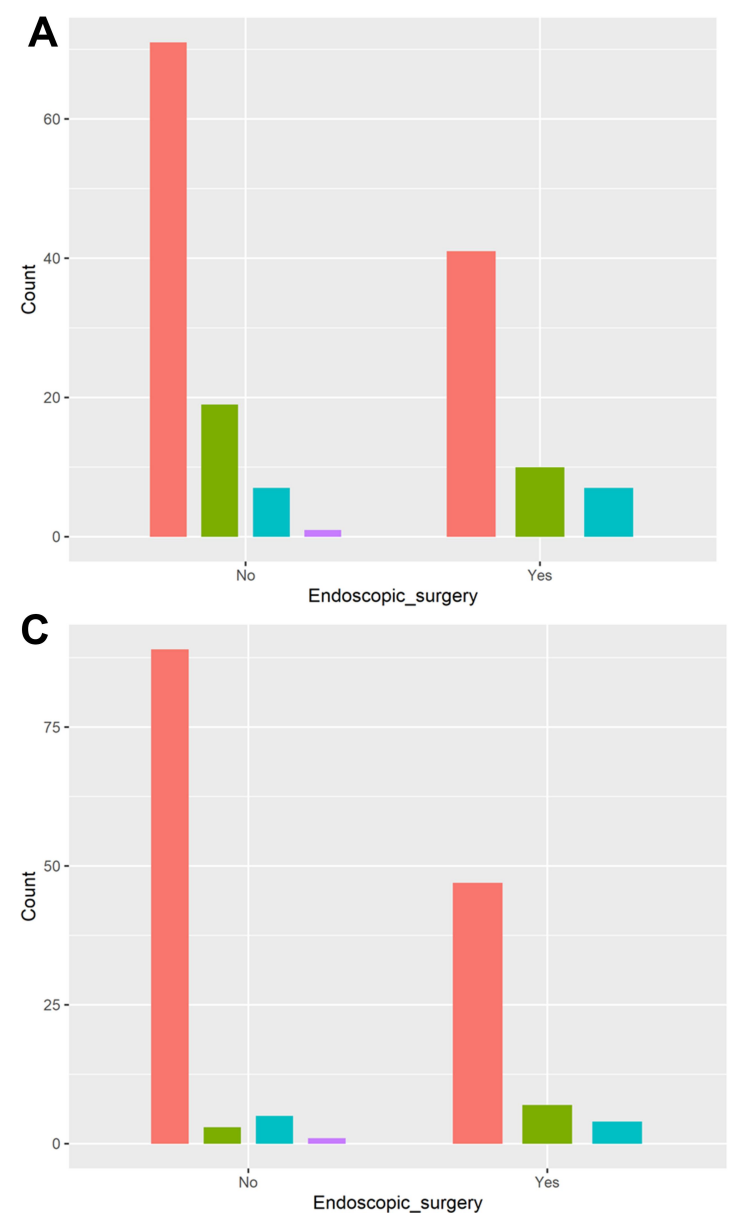
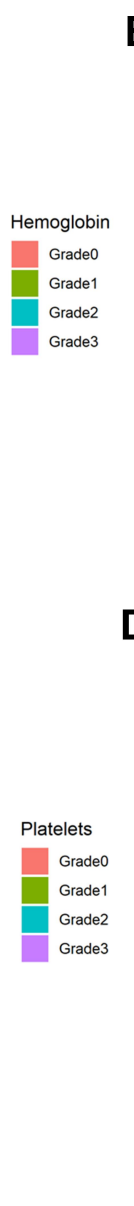
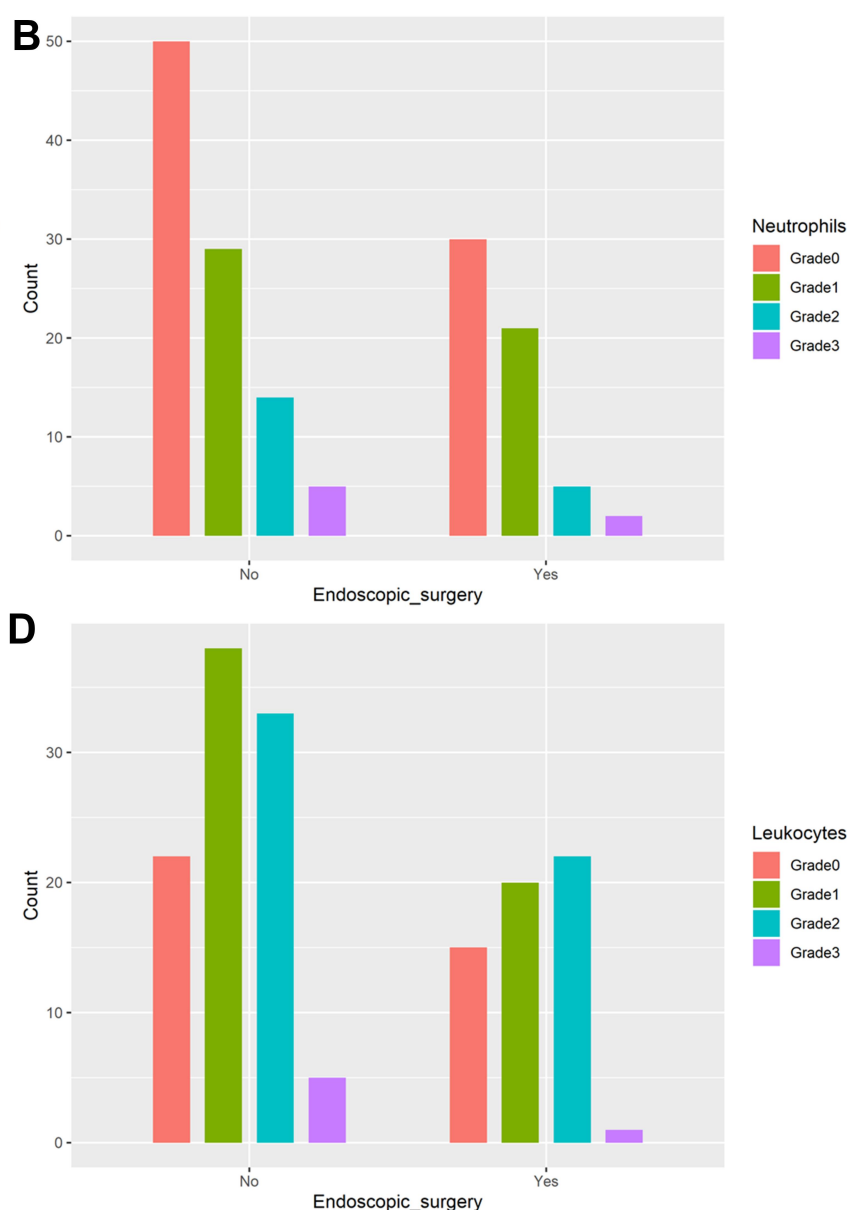

Figure 7 The hematologic toxicity between surgery and non-surgery group in patients with early-stage nasopharyngeal carcinoma $(\mathrm{n}=156$, all $\mathrm{P}>0.05)((\mathbf{A})$ Hemoglobin; $(\mathbf{B})$ Neutrophils; (C) Platelets; (D) Leukocytes).

pharyngeal mucosa will begin to change when the dose of radiotherapy ranges from $1500 \mathrm{cGy}$ to $2000 \mathrm{cGy}$, and oral and pharyngeal ulcers may occur when the dose reaches up to $3000 \mathrm{cGy}^{26}$ Compared with conventional radiotherapy, IMRT improves the local control rate and overall survival of NPC but is also associated with a higher incidence of severe radiationinduced oral mucositis (ROM). ${ }^{27}$ Furthermore, both the surgery and non-surgery groups showed similar rates of hematologic toxicity, which indicated that surgery did not increase the side effects of treatment. In addition to achieving complete resection of nasopharyngeal tumors, endoscopic nasopharyngectomy has the benefit of being minimally invasive and allowing faster postoperative recovery. Patients with cervical lymph node metastasis underwent functional neck dissection, which preserved the sternocleidomastoid muscle, internal and external jugular veins, and accessory nerve and had no effect on postoperative blood return.

This study has some limitations. First, the possibility of bias could not be eliminated because of the retrospective study design, but propensity score matching was performed to compensate. Second, some patients were not tested for EBV-DNA. Third, due to the limited number of N1 patients who underwent endoscopic nasopharyngectomy without neck dissection, the exact prognostic impact of neck dissection for NPC remains unclear and needs to be further clarified in future studies with a larger sample size.

In conclusion, surgery combined with chemoradiotherapy may be a safe and effective treatment modality for early-stage NPC. Further, it can reduce tumor residue and the occurrence of severe ROM, and improve the clearance rate of $\mathrm{EB}$ virus. 

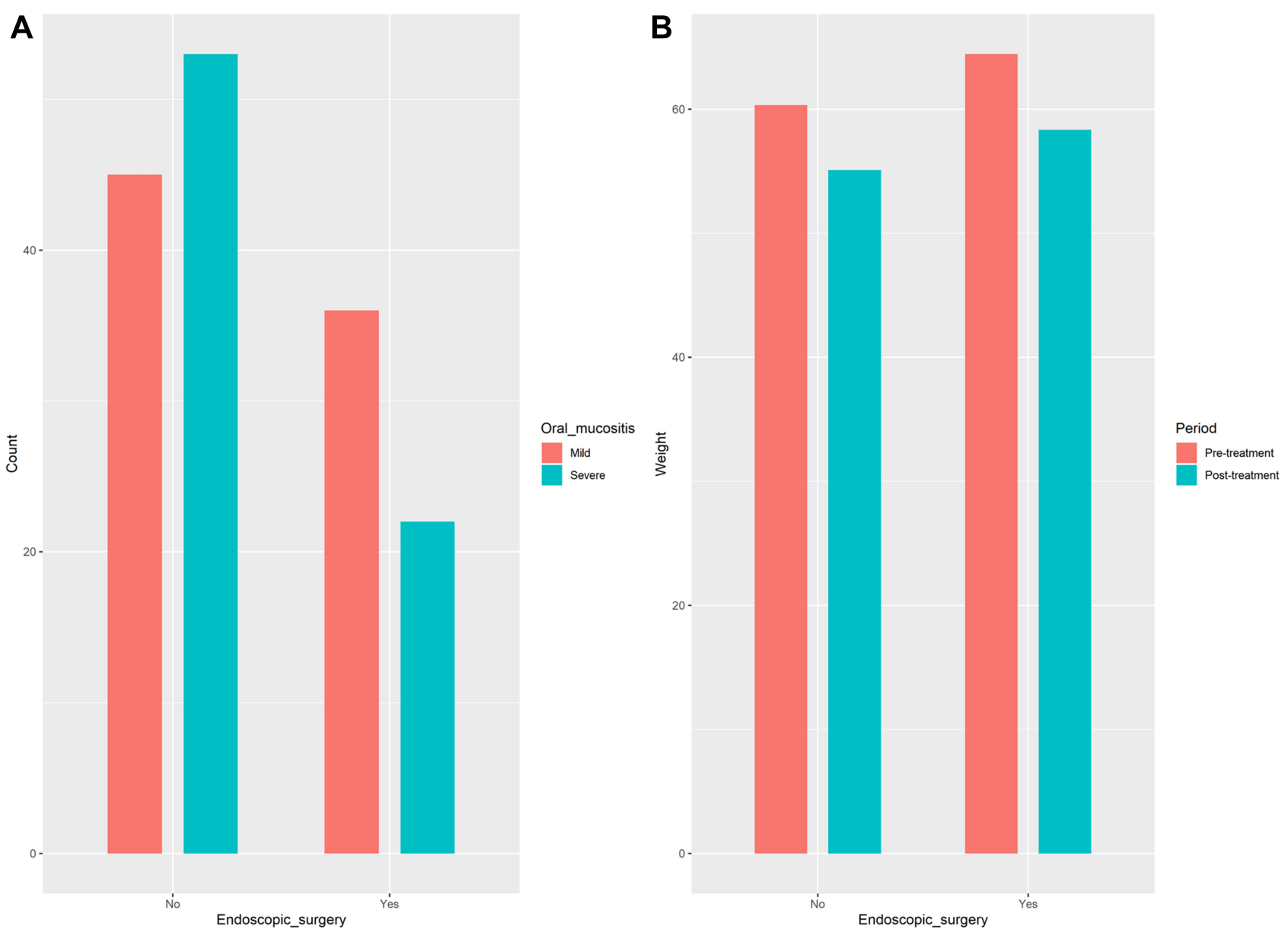

Figure 8 The grade of oral mucositis and weight change between surgery and non- surgery group in patients with early-stage nasopharyngeal carcinoma ( $\mathrm{n}=\mid 56$, both $\mathrm{P}>0.05)((\mathbf{A})$ Oral mucositis; (B) Weight change).

\section{Ethics Statement}

The Ethics Committee of The People's Hospital of Guangxi Zhuang Autonomous Region approved the study protocol, in accordance with the guidelines of the Helsinki Declaration. All patients provided written informed consent.

\section{Author Contributions}

All authors made substantial contributions to conception and design, acquisition of data, or analysis and interpretation of data; took part in drafting the article or revising it critically for important intellectual content; reviewed the manuscript and agreed on the journal to which the article will be submitted; agreed on all versions of the article before submission, during revision, the final version accepted for publication, and any significant changes introduced at the proofing stage; and agree to take responsibility and be accountable for the contents of the article.

\section{Funding}

This work was supported by the National Natural Science Foundation of China (81602390, 81960493, 81960186, and 81460097), Guangxi Natural Science Foundation (2016GXNSFCB380003 and 2017GXNSFAA198013), Open Research Project of Key Laboratory of HighIncidence-Tumor Prevention \& Treatment (Guangxi Medical University), Guangxi Key Research \& Development Program (GuiKeAB1850010), Guangxi Medical and Health Appropriate Technology Development and Promotion Application Project (S2018039), Scientific Research Project of Guangxi Health and Family Planning Commission (No. Z2014629). The funders had no role in the study design, data collection and analysis, decision to publish, or preparation of the manuscript.

\section{Disclosure}

The authors report no conflicts of interest in this work. 


\section{References}

1. Strieth S, Ernst BP, Both I, et al. Randomized controlled single-blinded clinical trial of functional voice outcome after vascular targeting KTP laser microsurgery of early laryngeal cancer. Head Neck. 2019;41(4):899-907. doi:10.1002/hed.25474

2. Jongekkasit I, Jitpratoom P, Sasanakietkul T, Anuwong A. Transoral endoscopic thyroidectomy for thyroid cancer. Endocrinol Metab Clin North Am. 2019;48(1):165-180. doi:10.1016/j.ecl.2018.11.009

3. Feng RM, Zong YN, Cao SM, Xu RH. Current cancer situation in China: good or bad news from the 2018 global cancer statistics? Cancer Commun (Lond). 2019;39(1):22. doi:10.1186/s40880-019-0368-6

4. Huang CL, Guo R, Li JY, et al. Nasopharyngeal carcinoma treated with intensity-modulated radiotherapy: clinical outcomes and patterns of failure among subsets of 8th AJCC stage IVa. Eur Radiol. 2020;30 (2):816-822. doi:10.1007/s00330-019-06500-5

5. Kong F, Zhou J, Du C, et al. Long-term survival and late complications of intensity-modulated radiotherapy for recurrent nasopharyngeal carcinoma. BMC Cancer. 2018;18(1):1139. doi:10.1186/ s12885-018-5055-5

6. King AD, Woo JKS, Ai QY, et al. Complementary roles of MRI and endoscopic examination in the early detection of nasopharyngeal carcinoma. Ann Oncol. 2019;30(6):977-982. doi:10.1093/annonc/ mdz106

7. Si YF, Lan GP, Deng ZX, et al. Influence of endoscopic sinus surgery on the quality of life of patients with early nasopharyngeal carcinoma and the analysis of prognosis-related factors. Tumour Biol. 2017;39 (7):1010428317707435. doi:10.1177/1010428317707435

8. Liu YP, Lv X, Zou X, et al. Minimally invasive surgery alone compared with intensity-modulated radiotherapy for primary stage I nasopharyngeal carcinoma. Cancer Commun (Lond). 2019;39 (1):75. doi:10.1186/s40880-019-0415-3

9. Liu SL, Sun XS, Li XY, et al. The diagnostic and prognostic values of plasma Epstein-Barr virus DNA for residual cervical lymphadenopathy in nasopharyngeal carcinoma patients: a retrospective study. Cancer Commun (Lond). 2019;39(1):14. doi:10.1186/s40880-019-0357-9

10. Liu J, Yu H, Sun X, et al. Salvage endoscopic nasopharyngectomy for local recurrent or residual nasopharyngeal carcinoma: a 10-year experience. Int J Clin Oncol. 2017;22(5):834-842. doi:10.1007/ s10147-017-1143-9

11. Eisenhauer EA, Therasse P, Bogaerts J, et al. New response evaluation criteria in solid tumours: revised RECIST guideline (version 1.1). Eur J Cancer. 2009;45(2):228-247. doi:10.1016/j.ejca.2008.10.026

12. Stoker SD, van Diessen JN, de Boer JP, Karakullukcu B, Leemans CR, Tan IB. Current treatment options for local residual nasopharyngeal carcinoma. Curr Treat Options Oncol. 2013;14 (4):475-491. doi:10.1007/s11864-013-0261-5

13. Lv JW, Zhou GQ, Li JX, et al. Magnetic resonance imaging-detected tumor residue after intensity-modulated radiation therapy and its association with post-radiation plasma epstein-barr virus deoxyribonucleic acid in nasopharyngeal carcinoma. $J$ Cancer. 2017;8 (5):861-869. doi:10.7150/jca.17957

14. Ng SH, Chang JT, Ko SF, Wan YL, Tang LM, Chen WC. MRI in recurrent nasopharyngeal carcinoma. Neuroradiology. 1999;41 (11):855-862. doi:10.1007/s002340050857
15. Comoretto M, Balestreri L, Borsatti E, Cimitan M, Franchin G, Lise M. Detection and restaging of residual and/or recurrent nasopharyngeal carcinoma after chemotherapy and radiation therapy: comparison of MR imaging and FDG PET/CT. Radiology. 2008;249(1):203-211. doi:10.1148/radiol.2491071753

16. Menon SS, Guruvayoorappan C, Sakthivel KM, Rasmi RR. Ki-67 protein as a tumour proliferation marker. Clin Chim Acta. 2019;491:39-45. doi:10.1016/j.cca.2019.01.011

17. Wei J, Pei S, Zhu X. Comparison of 18F-FDG PET/CT, MRI and SPECT in the diagnosis of local residual/recurrent nasopharyngeal carcinoma: a meta-analysis. Oral Oncol. 2016;52:11-17. doi:10.10 16/j.oraloncology.2015.10.010

18. Kwong DL, Nicholls J, Wei WI, et al. The time course of histologic remission after treatment of patients with nasopharyngeal carcinoma. Cancer. 1999;85(7):1446-1453. doi:10.1002/(SICI)1097-0142(19990401)85:7<1446::AID-CNCR4>3.0.CO;2-3

19. He Y, Zhou Q, Shen L, et al. A retrospective study of the prognostic value of MRI-derived residual tumors at the end of intensity-modulated radiotherapy in 358 patients with locally-advanced nasopharyngeal carcinoma. Radiat Oncol. 2015;10:89. doi:10.1186/s13014-015-0401-0

20. Yang X, Ren H, Yu W, et al. Analysis of clinical target volume delineation in local-regional failure of nasopharyngeal carcinoma after intensity-modulated radiotherapy. $J$ Cancer. 2020;11 (7):1968-1975. doi:10.7150/jca.39588

21. Lin JC, Wang WY, Chen KY, et al. Quantification of plasma Epstein-Barr virus DNA in patients with advanced nasopharyngeal carcinoma. N Engl J Med. 2004;350(24):2461-2470. doi:10.1056/ NEJMoa032260

22. To EW, Chan KC, Leung SF, et al. Rapid clearance of plasma Epstein-Barr virus DNA after surgical treatment of nasopharyngeal carcinoma. Clin Cancer Res. 2003;9(9):3254-3259.

23. Wang WY, Twu CW, Chen HH, et al. Plasma EBV DNA clearance rate as a novel prognostic marker for metastatic/recurrent nasopharyngeal carcinoma. Clin Cancer Res. 2010;16(3):1016-1024. doi:10.1158/1078-0432.CCR-09-2796

24. Pereira ER, Kedrin D, Seano G, et al. Lymph node metastases can invade local blood vessels, exit the node, and colonize distant organs in mice. Science. 2018;359(6382):1403-1407. doi:10.1126/science.aal3622

25. Wong EHC, Liew YT, Abu Bakar MZ, Lim EYL, Prepageran N. A preliminary report on the role of endoscopic endonasal nasopharyngectomy in recurrent rT3 and rT4 nasopharyngeal carcinoma. Eur Arch Otorhinolaryngol. 2017;274(1):275-281. doi:10.1007/s00405016-4248-2

26. Scully C, Epstein J, Sonis S. Oral mucositis: a challenging complication of radiotherapy, chemotherapy, and radiochemotherapy. Part 2: diagnosis and management of mucositis. Head Neck. 2004;26 (1):77-84. doi:10.1002/hed.10326

27. Kouloulias V, Thalassinou S, Platoni K, et al. The treatment outcome and radiation-induced toxicity for patients with head and neck carcinoma in the IMRT era: a systematic review with dosimetric and clinical parameters. Biomed Res Int. 2013;2013:401261. doi:10.11 $55 / 2013 / 401261$ 


\section{Publish your work in this journal}

Cancer Management and Research is an international, peer-reviewed The manuscript management system is completely online and includes open access journal focusing on cancer research and the optimal use of preventative and integrated treatment interventions to achieve improved a very quick and fair peer-review system, which is all easy to use. Visit http://www.dovepress.com/testimonials.php to read real quotes outcomes, enhanced survival and quality of life for the cancer patient.

from published authors. 